\title{
Investigating dementia literacy among community- dwelling adults and older adults in Macau: A mixed methods study
}

\section{Angela YM Leung ( $\sim$ angela.ym.leung@polyu.edu.hk)}

Hong Kong Polytechnic University School of Nursing https://orcid.org/0000-0002-9836-1925

Cindy S. U Leong

Macau Polytechnic Institute

Pak Leng Cheong

Kiang Wu Nursing College of Macau

Alice S. M. Tsang

Kiang Wu Nursing College of Macau

Bernice 0. C. Lam Nogueira

Macao Polytechnic Institute

Ming Liu

Macao Polytechnic Institute

lat Kio Van

Kiang Wu Nursing College of Macau

Daphne Cheung

Hong Kong Polytechnic University

Yao Jie Xie

Hong Kong Polytechnic University

Alice Yuen Loke

Hong Kong Polytechnic University

Alex Molassiotis

Hong Kong Polytechnic University

Research article

Keywords: caregivers, Chinese, dementia, dementia literacy, service needs

Posted Date: December 12th, 2019

DOI: https://doi.org/10.21203/rs.2.18630/v1 
License: (c) (i) This work is licensed under a Creative Commons Attribution 4.0 International License. Read Full License 


\title{
Investigating dementia literacy among community-dwelling adults and older adults in Macau: A mixed methods study
}

\begin{abstract}
Angela Yee Man Leung ${ }^{1,2}$, Cindy S. U Leong ${ }^{3}$, Pak Leng Cheong ${ }^{4}$, Alice S. M. Tsang ${ }^{4}$, Bernice O. C. Lam Nogueira ${ }^{3}$, Ming Liu ${ }^{3}$, Iat Kio Van ${ }^{4}$, Daphne S. K. Cheung ${ }^{1,2}$, Yao Jie Xie ${ }^{1}$, Olivia Fung ${ }^{1}$, Alice Yuen Loke ${ }^{1}$, Alex Molassiotis ${ }^{5}$
\end{abstract}

${ }^{1}$ School of Nursing, The Hong Kong Polytechnic University, Hong Kong, China

${ }^{2}$ Centre for Gerontological Nursing, School of Nursing, The Hong Kong Polytechnic University, Hong Kong, China

${ }^{3}$ Macau Polytechnic Institute, Macau, China

${ }^{4}$ Kiang Wu Nursing College of Macau, Macau, China

${ }^{5}$ World Health Organization Collaborating Centre for Community Health Services, The Hong Kong Polytechnic University, Hong Kong, China

Corresponding author: Angela Yee Man Leung, Director, Centre for Gerontological Nursing, School of Nursing, The Hong Kong Polytechnic University, Hung Hom, Kowloon, Hong Kong SAR, China

Tel: +852 27665587; E-mail: angela.ym.leung@polyu.edu.hk 
Abstract

2 Background: As population ageing and dementia incidence continue to increase worldwide,

3 health systems are urged to empower the public to address factors related to dementia. This 4 study aims to assess Macau citizens' knowledge of dementia, attitudes towards persons with 5 dementia, and help-seeking behaviours and intention toward dementia.

6

7 Methods: This is a mixed-methods study with both quantitative (cross-sectional survey) and 8 qualitative components (focus group interviews). The Alzheimer's Disease Knowledge Scale 9 (ADKS) and Dementia Attitude Scale (DAS) were utilized in the quantitative data collection, 10 whereas focus group interviews were employed to gather context-specific understanding of 11 dementia in the local setting. Descriptive statistics and Chi-square tests were used to analyze 12 quantitative data, while content analysis was used for qualitative data.

14 Results: The overall level of knowledge on dementia was low (ADKS mean total score $=17.38$, $15 \mathrm{SD}=3.31$ ), with the least amount of knowledge in the caregiving domain. Meanwhile, attitudes 16 toward persons with dementia was generally positive (mean $[\mathrm{SD}]=89.07$ [11.99]). Many of 17 the focus group participants were also uncertain regarding the availability of dementia services 18 in the region. The general public was interested to obtain dementia information through social 19 media.

21 Conclusions: Efforts should be made to build up dementia literacy in Macau, especially in 22 terms of caregiving. Information about dementia could be disseminated in social media and by 23 healthcare professionals.

25 Keywords: caregivers, Chinese, dementia, dementia literacy, service needs 


\section{Background}

27 Macau, one of the two Special Administrative Regions of China, is a small city with

28700,000 citizens; but in 2012, it ranked second on the list of countries and regions with the

29 longest life expectancy in the world, which is 84.43 years [1]. The Macau government is

30 making efforts to promote the provision of care for elderly people with chronic illnesses, while

31 dementia is one of the key health concerns that the government has prioritized [1]. As rates of

32 cognitive decline continue to increase [2], investigating dementia literacy in the region will

33 help in efforts to develop appropriate services for persons with dementia (PWD), in the

34 formulation of community education programmes, and in the development of relevant public

35 health policies for the region.

36 In Macau, there are about 4,000 PWD [3]. Despite the high prevalence of dementia in

37 the community, the Chinese general public does not possess sufficient knowledge about the

38 condition [4]. In a survey with 3,007 community-dwelling older adults in China (covering 34

39 urban cities), the overall dementia literacy was 55\% [5]; whereas another study among 354

40 elderly Chinese Americans revealed lower rates at 28.8\% [6]. 'Dementia literacy' has been

41 defined as "knowledge and beliefs regarding dementia that aid recognition, management or

42 prevention" [7]. There is a general consensus that dementia literacy is about more than

43 'knowledge of dementia'; and should also include 'beliefs regarding dementia' - that is,

44 'attitudes towards persons with dementia' and the 'intention to seek help'. People with negative

45 attitudes would feel uncomfortable when PWD are around them, and do not feel obligated to

46 support these patients [8].

47 Cultivating dementia literacy in the community reduces stigmatization and encourages

48 community members to provide essential support to patients and relatives $[9,10]$. Evidence has

49 been shown that stigmatization about dementia existed in Chinese community and this delayed

50 access to essential health services [11]. Developing dementia health literacy in the community 
51 is therefore essential, as doing so will support both patients and caregivers, and cultivate 52 harmony in society. Therefore, this study aims to: 1) assess knowledge of the prevalence, 53 symptoms, treatment options, and prognosis of dementia; 2) assess attitudes towards PWD; 54 and 3) assess help-seeking behaviour and intention in dementia.

\section{Methods}

57 This is a mixed-methods study with a quantitative (a cross-sectional survey) and a 58 qualitative component (focus group interviews). This design was employed to combine 59 elements of the two approaches that will provide a deeper understanding of the concept under 60 study [12]. Data collection was conducted in Macau from July 2017 to January 2018. There

61 were three key domains of dementia literacy: knowledge of dementia, attitudes towards PWD, 62 and help-seeking behaviour and intention.

63

64 Quantitative component: Cross-Sectional Survey

65 Survey measures

66 The survey written in Traditional Chinese includes three outcome measures: 67 Alzheimer's Disease Knowledge Scale (ADKS), Dementia Attitudes Scale (DAS), and mode 68 of delivering dementia information. ADKS is a 30 -item scale with true/false questions that 69 assess knowledge related to the assessment, diagnosis, caregiving, life impact, prevalence, 70 prevention, risk factors, symptoms, treatment, and management of Alzheimer's disease [13].

71 The internal consistency (Cronbach's alpha $=0.71)$ and its test-retest reliability (reliability 72 coefficient $=0.81, p<0.001)$ in the general population was good [13]. DAS is a 7-point Likert 73 scale (strongly disagree $=1$ and strongly agree $=7$ ), with Cronbach's alphas ranging from 0.83

74 to 0.85 [14]. The total score of the DAS is the sum of all of its items: the higher the score, the 75 more positive the attitudes towards PWD. 
76 The participants were asked to indicate the existing channels (television, leaflets,

77 WeChat, Facebook, etc.) and preferred channels for obtaining relevant information about

78 dementia services. A list of services or support to PWD in the community was given. The

79 respondents were also asked to rate their preference, ranging from " 0 " (least preferred) to "5"

80 (most preferred). Demographic information about the participants was collected.

81

82 Sample for the Surveys

83 Using a stratified sampling method, we recruited 200 Macau citizens to join the survey.

84 According to the population ratio in Macau [15], we approached 109 Macau citizens aged 15-

8544 (with 55 males and 54 females), 68 citizens aged 45-64 (34 males and 34 females), and 22

86 citizens aged 65 or above (11 males and 11 females) for the survey via non-governmental

87 organizations (NGOs) and personal networks. The inclusion criteria were: aged 18 or above,

88 cognitively intact (Short Portable Mental Status Questionnaire, SPMSQ >7), and able to read

89 Chinese or communicate in Cantonese or Putonghua; The exclusion criteria were: being 90 hospitalized and living in a residential care home.

91

Qualitative component: Focus group interviews

93

Three focus group interviews were conducted with two facilitators. A vignette showing

94 the symptoms of dementia was developed by the project team in consideration with the Chinese

95 cultural and contextual relevance in Macau [16]. A discussion was conducted based on the

96 contents of the vignette as well as the informants' experience. Guiding questions were used to

97 stimulate the informants to discuss issues related to dementia. Audio-tape recording of the

98 interviews was made, upon approval of the participants.

99

100 Sample for the Focus Group Interviews 
102 NGOs or through personal networks. The inclusion and exclusion criteria were the same as

103 those in the survey. People at different ages were invited, including older adults and caregivers.

104 Data analysis

105 Quantitative survey data were input and analyzed using IBM Statistical Package for the

106 Social Sciences (SPSS) version 23. Multiple imputation was used to handle missing values. A

107 descriptive analysis was conducted for the participant demographics, ADKS and DAS data,

108 and items for measuring help-seeking behaviour and intention. Interviews were transcribed

109 verbatim and content analysis was used. Three members of the project team coded the

110 transcription independently and identified the themes. A comparison of the codings was made,

111 and a consensus was reached after discussion.

112

113 Results

114 Profile of the participants

115 Table 1 shows the demographic characteristics of the participants in the survey. Half

$116(53.5 \%)$ were females and only $23.0 \%$ of the respondents had previous contact with a person

117 with dementia. Another 23 Macau adults were included in the three focus group interviews.

118

Table 1. Demographics of the participants in the survey and the focus group interviews

\begin{tabular}{lcccc} 
& \multicolumn{2}{c}{$\begin{array}{c}\text { Survey } \\
(\mathrm{n}=200)\end{array}$} & \multicolumn{2}{c}{$\begin{array}{c}\text { Focus group } \\
\text { interviews }(\mathrm{n}=23)\end{array}$} \\
\hline Demographic characteristics & Count & $\%$ & Count & $\%$ \\
\hline Sex & & & & \\
\multicolumn{1}{l}{ Male } & 93 & $46.5 \%$ & 9 & $39 \%$ \\
Female & 107 & $53.5 \%$ & 14 & $61 \%$ \\
$18-44$ & 110 & $55.0 \%$ & 8 & $35 \%$ \\
$45-64$ & 68 & $34.0 \%$ & 9 & $39 \%$
\end{tabular}


$65+$

Employment status

Employed Full-time

Employed Part-time

Unemployed

Retired

Student

Housewife

Highest academic qualification

No formal schooling

Primary or below

Secondary

University/College

Master or Above

Marital status

Single

Married

Cohabited

Widowed

Divorced

Accomodation

Privately owned house/flat

Rented accommodation

Public/government Housing

Number of persons in the household

1

2

3

4
22

$$
11.0 \%
$$

6

$26 \%$

$\begin{array}{cccc}109 & 55.6 \% & 11 & 48 \% \\ 13 & 6.6 \% & 3 & 13 \% \\ 14 & 7.1 \% & 0 & 0 \% \\ 44 & 22.4 \% & 6 & 26 \% \\ 11 & 5.6 \% & 2 & 9 \% \\ 5 & 2.6 \% & 1 & 4 \%\end{array}$

$\begin{array}{cccc}6 & 3.0 \% & 0 & 0 \% \\ 34 & 17.3 \% & 5 & 22 \% \\ 87 & 44.2 \% & 8 & 35 \% \\ 64 & 32.5 \% & 6 & 26 \% \\ 6 & 3.0 \% & 4 & 17 \%\end{array}$

$\begin{array}{cccc}65 & 33.2 \% & 7 & 30 \% \\ 111 & 56.6 \% & 16 & 70 \% \\ 2 & 1.0 \% & 0 & 0 \% \\ 11 & 5.6 \% & 0 & 0 \% \\ 7 & 3.6 \% & 0 & 0 \%\end{array}$

$139 \quad 73.9 \% \quad 19 \quad 83 \%$

$22 \quad 11.7 \% \quad 4 \quad 17 \%$

27

$14.4 \%$

$0 \quad 0.0 \%$

$\begin{array}{cccc}17 & 9.1 \% & 2 & 9 \% \\ 32 & 17.1 \% & 1 & 4 \% \\ 55 & 29.4 \% & 9 & 39 \% \\ 53 & 28.3 \% & 6 & 26 \%\end{array}$




\begin{tabular}{lllll}
5 & 17 & $9.1 \%$ & 1 & $4 \%$ \\
6 or more & 13 & $7.0 \%$ & 2 & $9 \%$ \\
missing & & & 2 & $9 \%$ \\
\hline
\end{tabular}

119

120

121

122

123

124

125

126

127

Table 2. Responses to the 30-item Alzheimer's Disease Knowledge Scale (ADKS)

\begin{tabular}{lccccc} 
& Min. & Max. & Mean & SD & $>50 \%$ items were correct \\
\hline ADKS total score & 9.00 & 27.00 & 17.38 & 3.31 & $143(71.9 \%)$ \\
ADKS subscales: & & & & & \\
- Risk factors & 0 & 6 & 3.19 & 1.22 & $80(40.2 \%)$ \\
- Assessment and diagnosis & 0 & 4 & 2.35 & 0.98 & $93(46.7 \%)$ \\
- Symptoms & 0 & 4 & 2.47 & 1.09 & $99(49.7 \%)$ \\
- Disease progression & 0 & 4 & 2.27 & 0.96 & $88(44.2 \%)$ \\
- Life impact & 0 & 3 & 2.15 & 0.83 & $154(77.4 \%)$ \\
- Caregiving & 0 & 5 & 2.05 & 1.05 & $59(29.6 \%)$ \\
- Treatment and management & 1 & 4 & 2.91 & 0.93 & $134(67.3 \%)$ \\
Note. n=199 & & & & & \\
\hline
\end{tabular}

128

129 Knowledge about the symptoms of dementia

130

Half of the respondents $(99 / 199,49.7 \%)$ in the survey were able to give correct answers

131 to more than half of the items relating to dementia symptoms (there were 4 items in this 
132

133

134

135

136

137

138

category) (Table 2). In the focus group interviews, the informants were able to describe symptoms of dementia such as the inability to name relatives, the loss of self-care ability, and forgetting to turn off the stove after cooking (please refer to Table 3 for the direct quotations from the focus group interviews).

\section{Table 3. Direct quotations from focus group interviews}

\begin{tabular}{|c|c|}
\hline Theme/concept & Direct quotations \\
\hline $\begin{array}{l}\text { Dementia is } \\
\text { prevalent in } \\
\text { Macau }\end{array}$ & $\begin{array}{l}\text { Not many, but still there are (people with dementia). I think that ... the } \\
\text { proportion of older adults ... in the overall dementia population ... is } \\
\text { around } 30 \% . \\
\text { It [Dementia] is common among the elderly. A few said that they have } \\
\text { relatives with dementia. }\end{array}$ \\
\hline $\begin{array}{l}\text { Under-reporting } \\
\text { of dementia } \\
\text { cases in Macau }\end{array}$ & $\begin{array}{l}\text { I think now there are more (dementia cases). In the past, we did not talk } \\
\text { about it or we did not know about it... Some (people) can have } \\
\text { (dementia) at a young age. In other words, it is not an illness only for } \\
\text { people in their seventies, eighties.... }\end{array}$ \\
\hline $\begin{array}{l}\text { Knowledge } \\
\text { about the } \\
\text { symptoms of } \\
\text { dementia }\end{array}$ & $\begin{array}{l}\text { The medicine has been taken, but he/she said that the medicine has not } \\
\text { been taken ... the nurse in the hospital said that he/she has taken the } \\
\text { medication.... For example, he/she forgot to turn off the fire after the } \\
\text { water had boiled.... Or he/she mistook sugar for salt ... they can't take } \\
\text { care of their own living ... they forgot how to come back home when they } \\
\text { went out.... } \\
\text { Yes, he is so senile that he cannot remember anything ... he cannot } \\
\text { recognize himself or his own children. } \\
\text { For instance, he/she might mistake the refrigerator for the wardrobe and } \\
\text { vice versa, and put the clothes into the refrigerator ... and put the food, } \\
\text { vegetables, and fish into the wardrobe. }\end{array}$ \\
\hline $\begin{array}{l}\text { Assessment and } \\
\text { diagnosis is the } \\
\text { first step in the } \\
\text { whole process }\end{array}$ & $\begin{array}{l}\text { I suggest that he/she consult a doctor first. In fact, a dementia medical } \\
\text { centre opened in Macau in September of last year. I think that he/she } \\
\text { should be assessed by a doctor ... and assessments, such as a cognitive } \\
\text { functioning assessment should be performed. If he/she is diagnosed with } \\
\text { dementia, medications might be used ... some brain training can be } \\
\text { received to help him/her. }\end{array}$ \\
\hline $\begin{array}{l}\text { Strategies to } \\
\text { support persons } \\
\text { with dementia }\end{array}$ & $\begin{array}{l}\text { Family members can make a nameplate for him/her if they allow him/her } \\
\text { to go out and return home... [Interviewer (simultaneously): Oh, Okay ... } \\
\text { make a nameplate for him/her]. Mark down the telephone number, } \\
\text { contact person, as well as his/her address... }\end{array}$ \\
\hline
\end{tabular}




\begin{tabular}{|c|c|}
\hline & $\begin{array}{l}\text { Talk about something that will interest him/her. Let him/her start a } \\
\text { topic, then gradually talk to him/her. They (PWD) mostly will talk about } \\
\text { their past and their childhood. We can guide them to talk about things in } \\
\text { the present. That is ... starting from the things in the past that they can } \\
\text { remember. When they start to talk about a topic, we talk to them } \\
\text { gradually.... When we talk more, they start to remember. Recently I } \\
\text { am ... When did you come and visit me? That is ... to start with their } \\
\text { topics, they normally talk about their past... } \\
\text { Some of the non-government funded or government-owned elderly } \\
\text { homes provide some places for ... people with dementia. In Macau, some } \\
\text { homes/hostels are specialized and accept people with dementia. }\end{array}$ \\
\hline $\begin{array}{l}\text { Understanding } \\
\text { of the prognosis } \\
\text { of dementia }\end{array}$ & $\begin{array}{l}\text { It seems that dementia ... cannot be altered from bad to normal. ... Same } \\
\text { for medication... It cannot reverse his/her illness... } \\
\text {...It is possible to] slow it down but it (dementia) cannot be cured. The } \\
\text { doctor said that it cannot be cured. The doctor has made it clear that ... } \\
\text { he/she cannot recover ... but ... for instance, if treatment is not received, } \\
\text { he/she may completely forget you within a year. If treatment is received, } \\
\text { it [the dementia] may slow down for three to four months. That is, } \\
\text { comparatively, it will slow down a bit, but he/she cannot recover. (The } \\
\text { doctor) has made it clear that yes, it can only be slowed down... } \\
\text { I think maybe it is okay for a year, but when it reaches the third year ... } \\
\text { and later ... I will think of their (PWD) friends in the community. How } \\
\text { about their friends or their families?... As their health continues to } \\
\text { deteriorate, it will get harder and harder for their caregivers. } \\
\text { At the late stage, the ability to swallow will be lost.... My friend's } \\
\text { mother at her late stage ... refused to eat. I think it was because she had } \\
\text { difficulty in swallowing... }\end{array}$ \\
\hline $\begin{array}{l}\text { Uncertain about } \\
\text { caregiving }\end{array}$ & $\begin{array}{l}\text { Not sure how to handle this ... not sure what should be done ... what is } \\
\text { the next step? ... If the conditions become worse, what should be done? } \\
\text { How do I know it is better now?... That is, we do not know ... that is, is it } \\
\text { becoming good or becoming bad? ... Well, what could be done to make it } \\
\text { better? }\end{array}$ \\
\hline $\begin{array}{l}\text { Attitudes } \\
\text { towards persons } \\
\text { with dementia: } \\
\text { respect PWD's } \\
\text { and family } \\
\text { members' } \\
\text { decision }\end{array}$ & $\begin{array}{l}\text { If they [PWD] disagree, they will not go there [nursing homes]. We } \\
\text { [caregivers] respect their [PWD] decisions. } \\
\text { Nevertheless, we had a discussion among the siblings, and (we) gave up } \\
\text { [applying for nursing homes]. (We) are not going to apply. Thus, it } \\
\text { rested on my family members ... to take care of him [the parent with } \\
\text { dementia]. We will also employ a maid to take care of him (24 hours a } \\
\text { day). Therefore, I think, this time it is also the family members who will } \\
\text { offer help to him. }\end{array}$ \\
\hline
\end{tabular}




\begin{tabular}{|c|c|}
\hline & $\begin{array}{l}\text { If the family members can take care of them (PWD), then of course it } \\
\text { will be better. If you cannot take care of them and need to go to work, } \\
\text { you can only place them there [in an elderly home]. No other solution. } \\
\text { Caregivers should possess the attributes like: they should care about and } \\
\text { love the PWD, they need to accompany and always talk to the PWD, and } \\
\text { they should be patient with the PWD and respect them. }\end{array}$ \\
\hline $\begin{array}{l}\text { Positive } \\
\text { attitude: feeling } \\
\text { guilty to locate } \\
\text { PWD to nursing } \\
\text { home }\end{array}$ & $\begin{array}{l}\text { No matter how, an elderly home ... she seems really ... Although we } \\
\text { have chosen a better elderly home for her, she will still be ... in fact (we) } \\
\text { think that her life has become more boring and that [she] has [had to } \\
\text { deal with] some changes [Interviewer (simultaneously): Yes...] and her } \\
\text { quality of life has been lowered. }\end{array}$ \\
\hline $\begin{array}{l}\text { Negative } \\
\text { attitudes } \\
\text { towards PWD: } \\
\text { Worry about } \\
\text { the safety issues }\end{array}$ & $\begin{array}{l}\text { I live next to with him [PWD]. If he is cooking ... selfishly speaking ... it } \\
\text { is really dangerous. I am really worried about it. } \\
\text { The older people and the children are living together. When he [PWD] } \\
\text { has an outbreak of symptoms, he can be ... very emotional sometimes.... } \\
\text { This will scare the children. } \\
\text { When he [person with dementia] is scolding someone, it is better not to } \\
\text { stimulate him. People with dementia can lose control of their emotions } \\
\text { [Interviewer (simultaneously): Yes...]. They can scold people, and } \\
\text { sometimes even beat others. If you go further and trigger them ... Since } \\
\text { you are not their relatives ... The most important point ... is that ... I will } \\
\text { choose to stay away from them ... because ... (I) do not know how crazy } \\
\text { they can get... }\end{array}$ \\
\hline $\begin{array}{l}\text { Negative } \\
\text { attitudes: whose } \\
\text { responsibility? }\end{array}$ & $\begin{array}{l}\text { We think that the most difficult time was going with her frequently for } \\
\text { follow-up consultations. And the other thing was 'who would go this } \\
\text { time?' Maybe we have a comparatively large family. Among us ... who } \\
\text { was the one who took the responsibility to take care of her? ... This } \\
\text { caused ... some bigger conflicts within the family. }\end{array}$ \\
\hline $\begin{array}{l}\text { Help seeking } \\
\text { and intention: } \\
\text { willing to find } \\
\text { out }\end{array}$ & $\begin{array}{l}\text { Actually, we are not quite sure in Macau which department provides this } \\
\text { service [dementia service]... but we will find out ... because Macau is a } \\
\text { small place.... If it really happens, we will ask about ... which is the } \\
\text { appropriate department? ... [and] how to provide point-to-point } \\
\text { service? }\end{array}$ \\
\hline $\begin{array}{l}\text { Channels for } \\
\text { getting } \\
\text { dementia } \\
\text { information }\end{array}$ & $\begin{array}{l}\text { Television is the best (channel). And ... or on the bus, post more posters. } \\
\text { These methods can reach the majority of people. } \\
\text { For dementia education ...we could target for caregivers, middle-aged } \\
\text { people, and retirees. They are very close to persons with dementia. }\end{array}$ \\
\hline $\begin{array}{l}\text { Help-seeking } \\
\text { behaviour: }\end{array}$ & $\begin{array}{l}\text { Family members are important. If the family members really cannot not } \\
\text { handle it ...when it becomes worse and more severe, you should consult }\end{array}$ \\
\hline
\end{tabular}




\begin{tabular}{|l|l|}
\hline $\begin{array}{l}\text { Family member } \\
\text { is the first one } \\
\text { to approach }\end{array}$ & $\begin{array}{l}\text { a doctor. After that, you should consult a social worker. Ask the social } \\
\text { worker what can be done. This should help. }\end{array}$ \\
\hline $\begin{array}{l}\text { Challenges } \\
\text { encountered in } \\
\text { help-seeking }\end{array}$ & $\begin{array}{l}\text { What resources do we have? Usually, it is the family members ... who } \\
\text { will help him/her. The hospital only provides medications to him/her... } \\
\text { Every halfyear, he/she goes to the hospital for a follow-up consultation, } \\
\text { and medications will be provided. Then, he/she (a social worker) will } \\
\text { say: "Some centres provide this kind of (dementia) intervention. In } \\
\text { Macau there are many cases of senile dementia, therefore, it is difficult } \\
\text { to obtain the service. My ... social worker has given me a letter for my } \\
\text { mother to make an appointment for receiving (dementia) interventions. } \\
\text { We were in the queue and waited for more than 1.5 years; finally, we } \\
\text { decided to give up. }\end{array}$ \\
\hline $\begin{array}{l}\text { Help-seeking } \\
\text { behaviour: } \\
\text { suggestions of } \\
\text { facilities, and } \\
\text { the services } \\
\text { they know }\end{array}$ & $\begin{array}{l}\text { Ihope that there are rehabilitation centres to help those people (with } \\
\text { dementia). The Peak [the public hospital in Macau] is only one for } \\
\text { medical consultations. After the consultations, they need rehabilitation } \\
\text { centres. }\end{array}$ \\
$\begin{array}{l}\text { It seems that there is a service called "Personal Emergency Link } \\
\text { Service". Their staff will regularly [call] you.... For instance, you as an } \\
\text { older adult, after installing this service, the staff member will regularly } \\
\text { ring you and talk to you. }\end{array}$ \\
\hline
\end{tabular}

Knowledge about assessment and diagnosis

Most of the informants indicated that 'assessment and diagnosis' is the first step to caring for PWD. One informant indicated that Macau had just opened a Dementia Centre in

144 September 2016, and that its services were comprehensive. However, not all of the informants 145 were aware of this service. This finding was in line with the responses in the survey, in which 146 only half of the respondents $(93 / 199,46.7 \%)$ were able to give correct answers to the items 147 related to dementia assessment and diagnosis. 
150

151

152

153

154

155

156

157

158

159

160

161

162

165

166

167

168

169

170

171

172

173

174

The majority of the respondents to the survey $(134 / 199,67.3 \%)$ were able to give correct answers to more than half of the items under 'treatment and management'. In the focus group interviews, the informants cited various strategies to support PWD. For example, making a name tag for the PWD, on which the caregiver's name, address, and contact details can be shown. Some informants suggested to use music therapy, cognitive training, playing mahjong (a tile-based game which was developed in China in the early $20^{\text {th }}$ Century and remains a popular game in Chinese community) to help the patients. They believed that nursing homes were the last resort of support when dementia advanced.

\section{Knowledge about the prognosis of dementia}

Less than half of the Macau citizens $(88 / 199,44.2 \%)$ had a good knowledge of the prognosis of dementia. In the focus groups, some informants expressed that even if treatments were given, the cognition of PWD would continue to decline and the condition would be worse in 3 or 10 years. This might have an impact on caregivers, family members, and the community.

\section{Knowledge about caring for people with dementia}

In the survey, 'knowledge of caregiving' was ranked lowest among the seven kinds of knowledge about dementia. The mean score for caregiving was 2.05 (SD 1.05) out of 5, and only one-third of the respondents $(59 / 199,29.6 \%)$ correctly answered at least half of the items in this category. The majority of the respondents admitted that they were not very familiar with dementia (69\%) and felt frustrated because they did not know how to help people with dementia (58.5\%). Moreover, about two-fifth (44\%) admitted that they could not imagine caring for someone with dementia. In the focus group interviews, informants also admitted that they did not know how to handle PWD and what to do in caregiving. 
176

177

178

179

180

181

182

183

184

185

186

187

188

189

190

191

192

193

194

195

196

197

198

199
Attitudes towards persons with dementia

The DAS scores ranged from 52 to 121 , with the mean total scores (mean [SD] $=89.07$

[11.99]) indicating positive attitudes toward PWD. The majority of the respondents in the survey were not afraid of PWD (60.5\%) and felt that PWD could enjoy life (69.0\%); while in the focus group interviews, some informants thought that most of the neighbours would be willing to direct the PWD to go home when the PWD got lost. One informant asserted that family members used different resources (mostly within the family) to support the PWD, as they knew that they would need to wait for a long time to obtain government-funded PWD services. The quantitative data confirmed this point. A high percentage of the respondents $(75.5 \%)$ in the survey indicated that they could do a lot to improve the lives of PWD. A male informant indicated that he and his family members felt extremely guilty to their mother, even though she had been in a quality elderly home because she had been lonely and bored. By contrast, some respondents held negative attitudes towards PWD. About half of the respondents in the survey did not feel confident around PWD (47.0\%). In the focus group interviews, some informants indicated that they were afraid of being affected by PWD who might forget to turn off the stove and then walk away from home after cooking. One reported that her parent with dementia occasionally lost his temper, which scared the children who were living with him. Another informant suggested that when the PWD was in a bad temper, family members should not stimulate him and should keep well away from him. This was in line with the finding from the survey that about one-third of the respondents would avoid an agitated PWD (36\%).

\section{Help-seeking behaviour and intention}

Informants in the focus group interviews expressed that the information about dementia was insufficient in Macau. The most preferred modes of information delivery were television 
200 (45.5\%), hospital websites (42.5\%), and newspapers (39.0\%) (Table 4). Discrepancies were

201 found between the preferred mode and the existing mode of information delivery in television

202 (preferred vs existing mode: $45.5 \%$ vs $28.5 \%, \mathrm{p}<0.001$ ) and in other channels. About $30 \%$ of

203 the respondents preferred to receive information from Facebook and WeChat, but not much

204 information was being disseminated via these two social network sites at present. The

205 respondents considered their family members as the most important people in dementia care.

206 When family members were not available to provide help, resources from the community, such

207 as day care centres (183, 91.5\%), skills training services for patients and caregivers $(162,81 \%)$,

208 and caregiver support services $(162,81 \%)$, will be the useful services for patients and

209 caregivers. Nonetheless, two informants recalled the challenges that they faced when

210 attempting to access dementia services, as they did not know the required procedures.

Table 4. Comparison between the preferred and existing modes of delivering information about dementia services

\begin{tabular}{|c|c|c|c|c|c|}
\hline & \multicolumn{2}{|c|}{ Preferred mode } & \multicolumn{2}{|c|}{ Existing mode } & \multirow[b]{2}{*}{ p-value } \\
\hline & Frequency & Percent & Frequency & Percent & \\
\hline Television & 91 & 45.5 & 57 & 28.5 & $<0.001$ \\
\hline Hospital websites & 85 & 42.5 & 64 & 32.0 & $<0.001$ \\
\hline Newspapers & 78 & 39.0 & 67 & 33.5 & $<0.001$ \\
\hline Educational leaflets & 72 & 36.0 & - & - & - \\
\hline Government websites & 71 & 35.5 & 37 & 18.5 & $<0.001$ \\
\hline Facebook & 57 & 28.5 & - & - & - \\
\hline WeChat & 55 & 27.5 & - & - & - \\
\hline Radio & 47 & 23.5 & 40 & 20.0 & $<0.001$ \\
\hline Non-government websites & 41 & 20.5 & 29 & 14.5 & $<0.001$ \\
\hline Magazines & 31 & 15.5 & 19 & 9.5 & $<0.001$ \\
\hline Instagram & 16 & 8.0 & - & - & - \\
\hline $\mathrm{B} \operatorname{logs}$ & 12 & 6.0 & - & - & - \\
\hline Professionals & 91 & 45.5 & 46 & 23.0 & $<0.001$ \\
\hline Friends & 60 & 30.0 & 54 & 27.0 & $<0.001$ \\
\hline Relatives & 42 & 21.0 & 31 & 15.5 & $<0.001$ \\
\hline
\end{tabular}


214 This study is the first to investigate dementia literacy in Macau, one of the Special

215 Administrative Regions of China. The cultural context in Macau is unique as it has been

216 colonized by Portugal for more than 100 years, but the Chinese culture is well preserved and

217 continue to be maintained in the community. Aside from the previous investigation of dementia

218 literacy in 34 cities in China [5], this study contributed to our understanding of dementia

219 literacy in this special region. These findings have been summarized in Figure 1.

220

221

222

223

224

225

226

227

228

229

230

231

232

233

234

235

236

237

238
[Please insert Figure 1 here]

Figure 1. Conceptual Framework of Dementia Literacy

With the practice of filial piety in Chinese families [17], Macau citizens were most willing to support their parents with dementia although their knowledge about dementia symptoms and caregiving skills was not high. The ADKS total score in Macau was much lower than the scores achieved by American students, older adults, senior centre staff, dementia caregivers, and dementia professionals [13]. There are many reasons for the low level of dementia knowledge in Macau. One possible reason, as shown in the focus group interviews, was that people in the region 'do not talk about the illness'. This best represents the concept of harmony in Chinese culture [17], in which dementia is considered as a taboo and people try to hide this illness from others, or some people misunderstand dementia as a 'normal age-related memory loss problems' [8].

Many Macau citizens were not aware of the existence of dementia assessment services, although these services have been in place for several years. For instance, free-of-charge cognitive assessments have been offered in seven health centres in Macau since 2016 [19]. Notably, low levels of knowledge of treatment and care leads to delayed diagnosis and poor planning of treatment and care [18]. Therefore, the Macau government and service providers 
239 are recommended to put resources into publicizing how to access cognitive health services.

240 Upon receiving a diagnosis of dementia, cognitively impaired older adults will receive

241 subsequent follow-ups in a dementia clinic in the only public hospital in the region [19]. Other

242 than the government's initiatives, Kiang Wu Nursing College of Macau offers comprehensive 243 assessments, diagnosis, treatment, and support services for caregivers in its memory clinic [20].

244 Macau citizens were generally kind to persons with dementia, and they were willing to

245 talk, care for, and live with persons with dementia [21, 22]. Nonetheless, some respondents 246 were not comfortable about dealing with persons with dementia, particularly those with 247 agitated behaviour. Cultivating positive attitudes towards dementia should be encouraged so 248 that community members will be willing to develop contacts with PWD [22].

249 Traditional mass media outlets (such as television and newspapers) were the most 250 preferred modes of delivery. It is worth working with these media outlets to develop public 251 educational programmes about dementia and to introduce the availability of dementia services 252 in the region. A robust evaluation of these health education campaigns conducted via mass 253 media should be carried out so that the impact of mass media campaigns on knowledge, 254 attitudes, and behaviours can be assessed [23]. Another option for public education is social 255 media (Facebook, WeChat, Instagram), as a substantial number of respondents would like to 256 receive dementia information from these channels. Nonetheless, these channels have not been 257 fully utilized to promote dementia literacy. Social media has been shown to be an effective 258 channel for health education and for communication among health professionals [24]. For 259 example, developing an app for assessing dementia symptoms in older citizens is a project that 260 is worthy of support.

261

\section{Conclusions}


The findings show that although Macau citizens have positive attitudes toward PWD, there is inadequate knowledge in terms of caregiving. Additionally, there is inadequate information dissemination among the availability of dementia-related services in the region.

266 This study fills a gap in knowledge about dementia literacy and provide a good foundation for 267 subsequent studies on dementia. This also provide insights for practitioners to utilize in 268 developing appropriate strategies in dementia education in Chinese community. In terms of 269 policy development, the current study provides a clear picture of the level of awareness of 270 dementia in the society and the barriers to accessing the existing dementia services, thus 271 providing guidelines for programmes and interventions that can be developed to address the 272 identified problems.

$274 \quad$ Limitations

275 This study has several limitations. First, the scale for measuring the intention to seek 276 information was developed by the project team because we could not find a relevant validated 277 scale. Second, the informants in the focus group interviews expressed their views based on 278 their experiences. These views may not be representative of the views of all Macau citizens.

279

280 List of abbreviations

281 PWD: persons with dementia; ADKS: Alzheimer's Disease Knowledge Scale; DAS: Dementia 282 Attitude Scale; NGOs: non-governmental organizations; SPMSQ: Short Portable Mental Status 283 Questionnaire; SPSS: Statistical Package for the Social Sciences

285 Declarations 
287 Both the Hong Kong Polytechnic University Human Subjects Ethics Sub-committee 288 (HSEARS20170511002) and the Kiang Wu Hospital's Ethical Committee (reference number: 289 REC-2017.01) approved this study. The subjects were informed that they would not be put at 290 a disadvantage or be at risk of being neglected for treatment or services by the NGOs due to 291 their participation or non-participation in this study. All of the participants who enrolled in this 292 study provided their written informed consent to take part in it.

293

294 Availability of data and materials

295 The datasets generated and/or analyzed during the current study are not publicly available due 296 privacy and ethical restrictions but are available from the corresponding author on reasonable 297 request.

298

299 Consent for publication

300 Not applicable.

301

302 Competing interests

303 The authors declare that they have no competing interests.

304

$305 \quad$ Funding

306 This project was funded by the Galaxy Entertainment Group Foundation. The funding body 307 had no role in study design, data collection and analysis, preparation of the manuscript, or the 308 decision to publish.

309

310 Authors' contributions 
311 Study concept and design: Dr. AYM Leung, Prof. M Liu, Prof. IK Van, Prof. AY Loke, and

312 Prof. A Molassiotis

313 Funding application: Prof. M Liu, Prof. IK Van, Prof. AY Loke, and Prof. A Molassiotis

314 Ethical approval: Prof. M Liu, Prof. IK Van, Prof. AY Loke, and Prof. A Molassiotis

315 Acquisition of subjects and/or data: Dr. AYM Leung, Dr. CSU Leong, Dr. PL Cheong, and

316 Dr. ASM Tsang

317 Analysis and interpretation of data: Dr. AYM Leung, Dr. CSU Leong, Dr. PL Cheong, and

318 Dr. ASM Tsang, Dr. BOCL Nogueira, Dr. DSK Cheung, Dr. YJ Xie, Dr. O Fung, Prof. M

319 Liu, Prof. IK Van, Prof. AY Loke, and Prof. A Molassiotis

320 Preparation of manuscript: Dr. AYM Leung, Dr. CSU Leong, Dr. PL Cheong, and Dr. ASM

321 Tsang, Dr. BOCL Nogueira, Dr. DSK Cheung, Dr. YJ Xie, Dr. O Fung

322 Revision of manuscript: Prof. M Liu, Prof. IK Van, Prof. AY Loke, and Prof. A Molassiotis

323

324 Acknowledgements

325 The authors wish to acknowledge the invaluable contribution of the participants in the study.

326 Special thanks to Ms. Sara Lee, students from Macao Polytechnic Institute and Kiang Wu

327 Nursing College, staff of Caritas Macau, União Geral das Associações dos Moradores de

328 Macau - the Tele-assistant 'Peng On Tung' and the Community Youth Team, and the Macao

329 Youth Federation for their support and assistance in collecting data, and to the anonymous

330 reviewers for their thoughtful review and guidance. 


\section{References:}

1. Macau Daily Times. Macau: Macau second in the list of countries that lives the longest. http://macaudailytimes.com.mo/archive-2009-2014/macau/34715-macau-second-in-thelist-of-countries-that-live-the-longest.html. Accessed 10 May 2018.

2. Alzheimer's Disease International. London: World Alzheimer Report 2015. https://www.alz.co.uk/research/WorldAlzheimerReport2015.pdf. Accessed 12 March 2017.

3. Macau News and the Macau Post Daily. Macau: Nursing college in Macau to provide dementia tests. https://macaunews.mo/nursing-college-macau-provide-dementia-tests/. Accessed 20 April 2017.

4. Sheng B, Law CB, Yeung KM. Characteristics and diagnostic profile of patients seeking dementia care in a memory clinic in Hong Kong. Int Psychogeriatr. 2009;21:392-400. doi: 10.1017/S104161020800817X.

5. Zhang H, Loi SM, Zhou S, et al. Dementia Literacy among Community-Dwelling Older Adults in Urban China: A Cross-sectional Study. Front Public Health. 2017;5:124. doi:10.3389/fpubh.2017.00124.

6. Zheng X, Woo BKP. Association between recognizing dementia as a mental illness and dementia knowledge among elderly Chinese Americans. World J Psychiatry. 2016;6:2338. doi:10.5498/wjp.v6.i2.233.

7. Low LF, Anstey KJ. Dementia literacy: recognition and beliefs on dementia of the Australian public. Alzheimers Dement. 2009;5:43-9. doi: 10.1016/j.jalz.2008.03.011.

8. Cahill S, Pierce M, Werner P, Darley A, Bobersky A. A systematic review of the public's knowledge and understanding of Alzheimer's disease and dementia. Alzheimer Dis Assoc Disord. 2015;29: 255-75. doi: 10.1097/WAD.0000000000000102. 
9. Smith BJ, Ali S, Quach H. Public knowledge and beliefs about dementia risk reduction: a national survey of Australians. BMC Public Health. 2014;14:661.

10. Jorm AF. Mental health literacy: Public knowledge and beliefs about mental disorders. $\mathrm{Br}$ J Psychiatry. 2000;177:396-401.

11. Woo BK, Mehta P. Examining the differences in the stigma of dementia and diabetes among Chinese Americans. Geriatr Gerontol Int 2017; 17:760-764. doi: 10.1111/ggi.12782.

12. Johnson BR, Onwuegbuzie AJ, Turner LA. Toward a definition of mixed methods research. J Mix Methods Res. 2007;1:112-33. doi: 10.1177/1558689806298224.

13. Carpenter BD, Balsis S, Otilingam PG, Hanson PK, Gatz M. The Alzheimer's Disease Knowledge Scale: development and psychometric properties. Gerontologist. 2009;49:23647. doi: 10.1093/geront/gnp023.

14. O'Connor ML, McFadden SH. Development and psychometric validation of the Dementia Attitudes Scale. Int J Alzheimers Dis. 2010;2010:1-10. doi: 10.4061/2010/454218.

15. Statistics and Census Service of the Government of Macao Special Administrative Region. Macau: Statistic Database. https://www.dsec.gov.mo/TimeSeriesDatabase.aspx. Accessed 02 July 2017.

16. Loi SM, Lautenschlager NT. Dementia literacy in older adults. Asia Pac Psychiatry. 2015; 7:292-7. doi: 10.1111/appy.12153.

17. Sun F, Ong R, Burnette D. The influence of ethnicity and culture on dementia caregiving: A review of empirical studies on Chinese Americans. Am J Alzheimers Dis Other Demen. 2012;27:13-22. doi: 10.1177/1533317512438224.

18. Werner P. Knowledge about symptoms of Alzheimer's disease: correlates and relationship to help-seeking behaviour. Int J Geriatr Psychiatry. 2003;18:1029-36. doi: 10.1002/gps.1011. 
19. Macau Dementia Friendly Community [Internet]. Macau: Macau Dementia Friendly Community. https://www.ssm.gov.mo/apps1/mdfc/ch.aspx\#clg12684-vlg12706. Accessed 10 May 2018.

20. Kiang Wu Nursing College of Macau [Internet]. Macau: Dementia early detection and prevention programme. http://www2.kwnc.edu.mo/?page_id=17479. Accessed 10 May 2018.

21. Aihara Y, Sugiyama T, Kato H, Ishi K, Goto Y. Public attitudes towards people living with dementia: a cross-sectional study in urban Japan (innovative practice). Dementia. 2016;19. doi: $10.1177 / 1471301216682118$.

22. Cheston R, Hancock J, White P. A cross-sectional investigation of public attitudes towards dementia in Bristol and South Gloucestershire using the Approaches to Dementia Questionnaire. Int Psychogeriatr. 2016;28:1717-24. doi: 10.1017/S1041610216000843

23. Kite J, Gale J, Grunseit A, Bellew W, Li V, Lloyd B, Maxwell M, Vineburg J, Bauman A. Impact of the Make Healthy Normal mass media campaign (Phase 1) on knowledge, attitudes and behaviours: a cohort study. Aust N Z J Public Health. 2018;42(3):269-76. doi: 10.1111/1753-6405.12779.

24. Chan WSY, Leung AYM. Use of social network sites for communication among health professionals: A systematic review. JMIR Med Educ. 2018;20:e117. doi: 10.2196/jmir.8382. 
331

332

333

334

335

336

337

338

339

340

341

342

343

344

345 


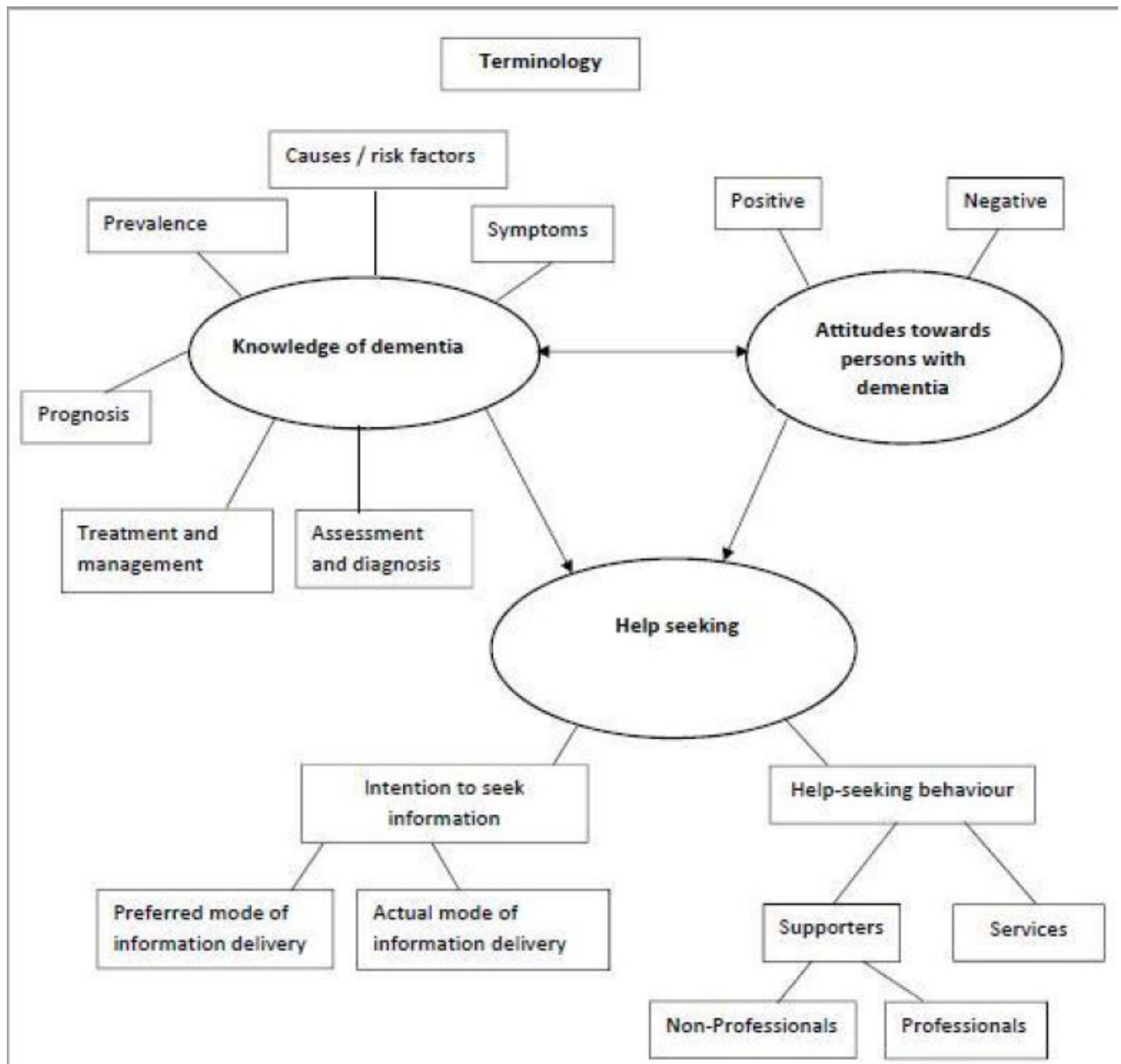

Figure 1

Conceptual Framework of Dementia Literacy 